\title{
Sandbox modeling of fault formation and evolution in the Weixinan Sag, Beibuwan Basin, China
}

\author{
Tong Hengmao* \\ State Key Laboratory of Petroleum Resource and Prospecting, China University of Petroleum, Beijing 102249, China \\ (C) China University of Petroleum (Beijing) and Springer-Verlag Berlin Heidelberg 2012
}

\begin{abstract}
Fault formation and evolution in the presence of multiple pre-existing weaknesses has not been investigated extensively in rift basins. The fault systems of Weixinan Sag, Beibuwan Basin of China, which is fully covered with high-precision 3-D seismic data and is rich in oil-gas resources, have been successfully reproduced by sandbox modeling in this study with inclusion of multiple preexisting weaknesses in the experimental model. The basic characteristics of fault formation and evolution revealed by sandbox modeling are as follows. 1) Weakness-reactivation faults and weakness-related faults are formed much earlier than the distant-weakness faults (faults far away from and with little or no relationship to the weakness). 2) Weakness-reactivation faults and weakness-related faults develop mainly along or parallel to a pre-existing weakness, while distant-weakness faults develop nearly perpendicular to the extension direction. A complicated fault system can be formed in a fixed direction of extension with the existence of multiple pre-existing weaknesses, and the complicated fault system in the Weixinan Sag formed gradually in a nearly N-S direction with multiple pre-existing weaknesses. 3) The increase in the length and number of faults is closely tied to the nature of pre-existing weaknesses. The sandbox model may provide a new clue to detailed fault system research for oil and gas exploration in rift basins.
\end{abstract}

Key words: Fault system, rift basin, multiple pre-existing weaknesses, Weixinan Sag, sandbox modeling

\section{Introduction}

The Weixinan Sag is a tectonic unit of the Beibuwan Cenozoic rift basin in the south-western continental shelf of the South China Sea (Fig. 1), where $\mathrm{E}_{1 \mathrm{c}} \mathrm{-Q}$ sedimentation developed (Table 1). Beibuwan, along with Yinggehai, Qiongdongnan and Zhujiangkou, are four basins developed in the north continental shelf of the South China Sea. Different from the other three basins, Beibuwan is a rift basin developed on the pre-Cenozoic basement. A continental rifting sequence (terrestrial phases) developed in the Paleogene, and a depression sequence (marine phases) developed in the Neogene and Quaternary (Table 1).

The Weixinan Sag is a petroleum-rich sag and the reservoirs found in the Weixinan Sag are mainly faultedblock or fault-related reservoirs. Research on fault systems has important significance in oil and gas exploration for the Beibuwan Basin and the whole South China Sea.

The fault system in the Weixinan Sag is very complicated. According to previous work from 2D seismic data interpretation, the origin of the fault system in the Weixinan Sag was the superposition of three phases of deformations

*Corresponding author. email: tong-hm@163.com

Received September 2, 2011
(Yan et al, 2005). However, such conclusion does not disclose the nature of the fault system and the level of its agreement with 3D seismic data is controversial. In this study, on the basis of systematic structural interpretation of 3D seismic data, and applying sandbox modeling, the fault system origin and fault formation and evolution were studied.

Analogue experiments have long been accepted as an important means of understanding the process and mechanism of structural deformation (Ma, 1987; Eisenstadt and Sims, 2005; Patton, 2005), and the effectiveness of sandbox modeling for rift basins has been widely recognized (McClay and Ellis, 1987; McClay, 1990; McClay and White, 1995; Acocella et al, 2000; Dooley et al, 2003; Tong, 2003; Tong et al, 2010; Tong and Yin, 2011; Zhou et al, 2007). On the basis of systematic analysis of geometric characteristics of fault systems, and in view of the deformation since the Oligocene (the major deformation stage in the Weixinan Sag), the fault system formation and evolution were simulated with sandbox experiments. The results showed that the fault system characteristics were successfully reproduced with near $\mathrm{N}-\mathrm{S}$ extension and considering multiple pre-existing fabrics (weaknesses). The experiment results agree well with the 3D seismic interpretation. They indicate that the complicated fault system in the Weixinan Sag gradually formed in a fixed extension direction under multiple pre-existing fabrics 


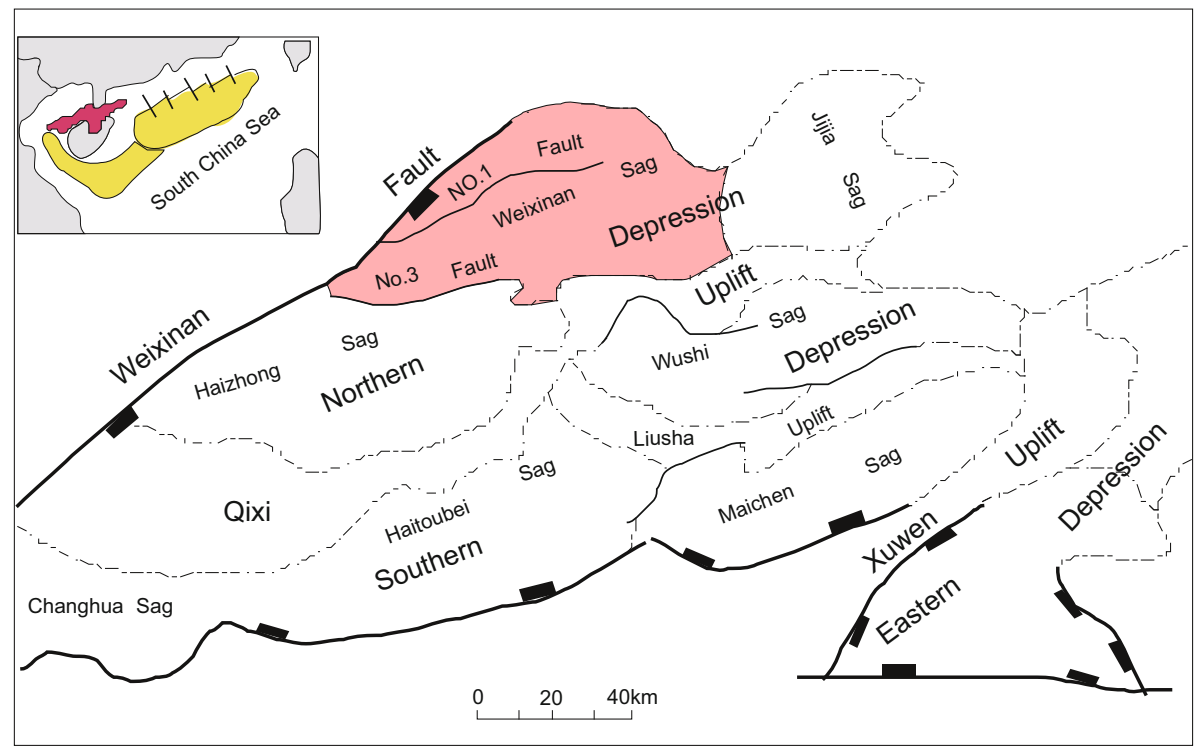

Fig. 1 Distribution of tectonic units of the Beibuwan Basin and the location of the Weixinan Sag (pink area). The small inset in the top left corner shows the location of the Beibuwan Basin (red area), and the yellow area includes three basins in the north of South China Sea: Yinggehai Basin, Qiongdongnan Basin and Zhujiangkou Basin

Table 1 Stratigraphic and tectonic evolution stages in the Beibuwan Basin

\begin{tabular}{|c|c|c|c|c|c|}
\hline System & Series & Formation & Member & $\begin{array}{l}\text { Age of the } \\
\text { bottom, Ma }\end{array}$ & $\begin{array}{c}\text { Evolution } \\
\text { stage }\end{array}$ \\
\hline N-Q & & & & 23.3 & Depression \\
\hline \multirow{7}{*}{ E } & \multirow{4}{*}{$\mathrm{E}_{3}$} & \multirow{3}{*}{ Weizhou $\left(\mathrm{E}_{3 \mathrm{~W}}\right)$} & $\mathrm{E}_{3 \mathrm{~W}}{ }^{1}$ & & \multirow{7}{*}{ Rifting } \\
\hline & & & $E_{3 w^{2}}$ & & \\
\hline & & & $E_{3 w}{ }^{3}$ & 32 & \\
\hline & & \multirow{3}{*}{ Liushagang $\left(\mathrm{E}_{2-31}\right)$} & $\mathrm{E}_{31}{ }^{1}$ & 38 & \\
\hline & \multirow{2}{*}{$\mathrm{E}_{2}$} & & $\mathrm{E}_{21}^{2}$ & & \\
\hline & & & $\mathrm{E}_{21}^{3}$ & 56.5 & \\
\hline & $\mathrm{E}_{1}$ & Changliu $\left(\mathrm{E}_{1 \mathrm{c}}\right)$ & & 65 & \\
\hline
\end{tabular}

instead of multi-phase deformation superimposition, and the fault system has remarkable regularity. This understanding is valuable for $3 \mathrm{D}$ seismic data interpretation and oil \& gas exploration.

There are numerous papers on the fundamental characteristics of fault formation, propagation and linkage, and fault displacement-length relationships in rift basins (Barnett et al, 1987; Walsh and Watterson, 1988; Peacock and Sanderson, 1991; Cartwright et al, 1995; Huggins et al, 1995; Acocella et al, 2000; Morley, 2007). However, the previous published information about fault formation and evolution is mainly for homogeneous geological bodies, while fault development under more complex conditions with multiple pre-existing weaknesses has not been extensively investigated.

Based on the interpretation of three dimensional seismic data and mechanical analysis, Morley et al (2004) proposed a geological model to reveal a general law of weakness reactivation in rift basins. Pre-existing weakness, which is oblique to the extension direction, is considered also in the oblique extension model (Withjack and Jamison, 1986; McClay and White, 1995; Boccaletti et al, 1998; Crider, 2001; Morley et al, 2004; Morley, 2007; Aragón-Arreola et al, 2005; Karlstrom and Manga, 2006). However, only boundary pre-existing weakness, which controls the boundary fault in rift basins instead of the inner basins, is considered in the previous model (including the oblique extension model). In fact, pre-existing weaknesses may exist in inner rift basins, particularly in China, where the basement of major rift basins has experienced a complicated tectonic evolution history (Tian and Zhang, 1996; Lu et al, 1997). In order to truly simulate the complex fault formation and evolution, both boundary and inner pre-existing weaknesses (e.g., multiple pre-existing weaknesses) should be considered in the model.

This study investigated fault formation and evolution with multiple pre-existing weaknesses based on sandbox modeling of the Weixinan Sag. Considering multiple preexisting weaknesses in the experimental model, the structural characteristics of fault distribution and evolution were well reproduced when compared with the results of $3 \mathrm{D}$ seismic data interpretation and balanced evolution section analysis. So the experimental results and deformation process provided a good insight into the fault formation and evolution with multiple pre-existing weaknesses in rift basins.

\section{The characteristics of the fault systems in the Weixinan Sag}

Because $\mathrm{E}_{31}{ }^{1}$ is the most important reservoir member of the Weixinan Sag, it was chosen as the simulation target of sandbox modeling.

Based on the systematic interpretation of 3-D seismic data, the fault system characteristics of $E_{31}{ }^{1}$ and other Eogene series in the area can be summarized as follows (Figs. 2 and 3(a)): 


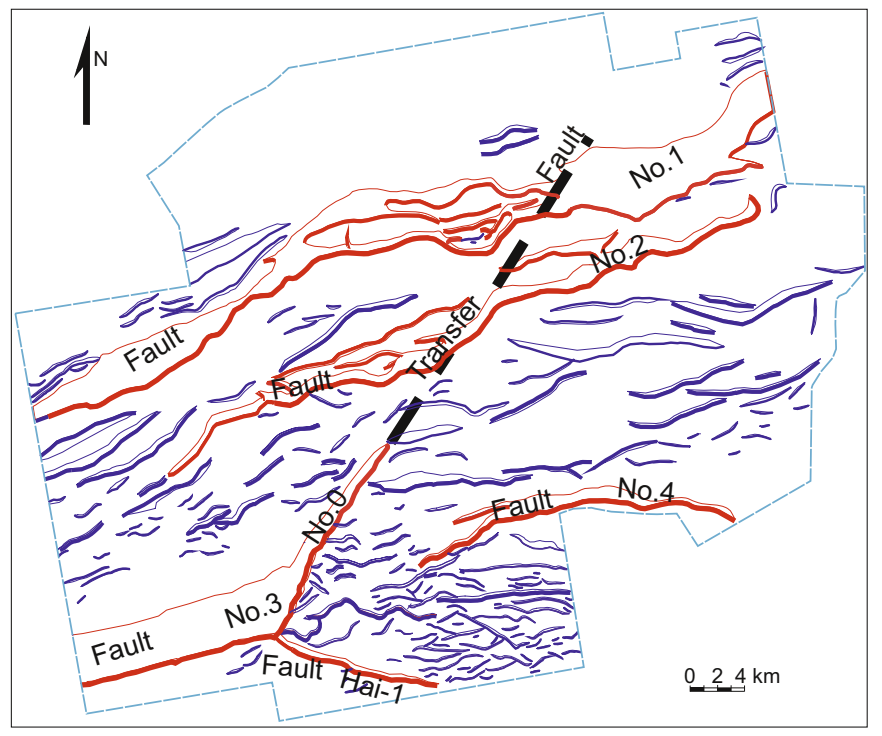

Fig. 2 Fault distribution map at the bottom of the Changliu Formation in the Weixinan Sag from 3-D seismic data interpretation, where the red lines are the major faults and the blue lines are secondary faults
1) Faults No.1, No.2 and No.3 are the major faults of the sag, all are ENE-trending and dip southward. Fault Hai-1 is not a major fault, NW-trending and intersects with Fault No.3. Fault No.1 is located in the north of the sag, and is a boundary fault. Fault No.3 is the south boundary of the sag with the largest throw. It acts as a boundary fault of the Haizhong Sag. To the east, Fault No.3 terminates suddenly on the No.0 transfer fault zone which is the major transfer fault zone in the sag and NNE-trending, and branches out into numerous, small scale, EW-trending faults in the east. Fault No.2 is a major fault inside the sag. It is an almost continuous, ENEtrending fault on top of the basement (Fig. 2), and changes upward (above $\mathrm{E}_{21}{ }^{2}$ ) into a series of EW-trending en echelon faults (Fig. 3(a)).

2) There are faults in four directions; most of them are ENE- and near EW-trending, and a few are NE- and NW-trending. The fault direction has systematic changes in different reflection layers, as shown in the following aspects (Fig. 4): the average fault strike is characterized by a clockwise rotation, that is, the average strike changes from


Fig. 3 Comparison between the 3-D seismic data interpretation and sandbox modeling results. (a) Fault system distribution at the bottom of first member of the Liushagang Formation from 3-D seismic data interpretation, where the rectangular box (inside the dotted line) is the modeling region; (b) Plan view of sandbox modeling results and interpretation (the number is fault formation order)

ENE at the bottom of the sag to nearly EW on the top of the Eogene series.

3) With Fault No.4 and its southwest extension line as a demarcation, faults on the northwest side mostly dip northward, while faults on the other side dip southward, but the strike is almost the same.

The quality of 3-D seismic data in the Weixinan Sag is excellent, and there is an extremely stable regional marker bed, the thick $\mathrm{E}_{21}{ }^{2}$ mudstone, in the entire sag. Therefore the characteristics of the fault system from interpretation of the 3-D seismic data should accurately reflect the actual geological conditions of the Weixinan Sag.

To explain all these structural features, the following experimental model with multiple pre-existing weaknesses is designed for the fault modeling. 


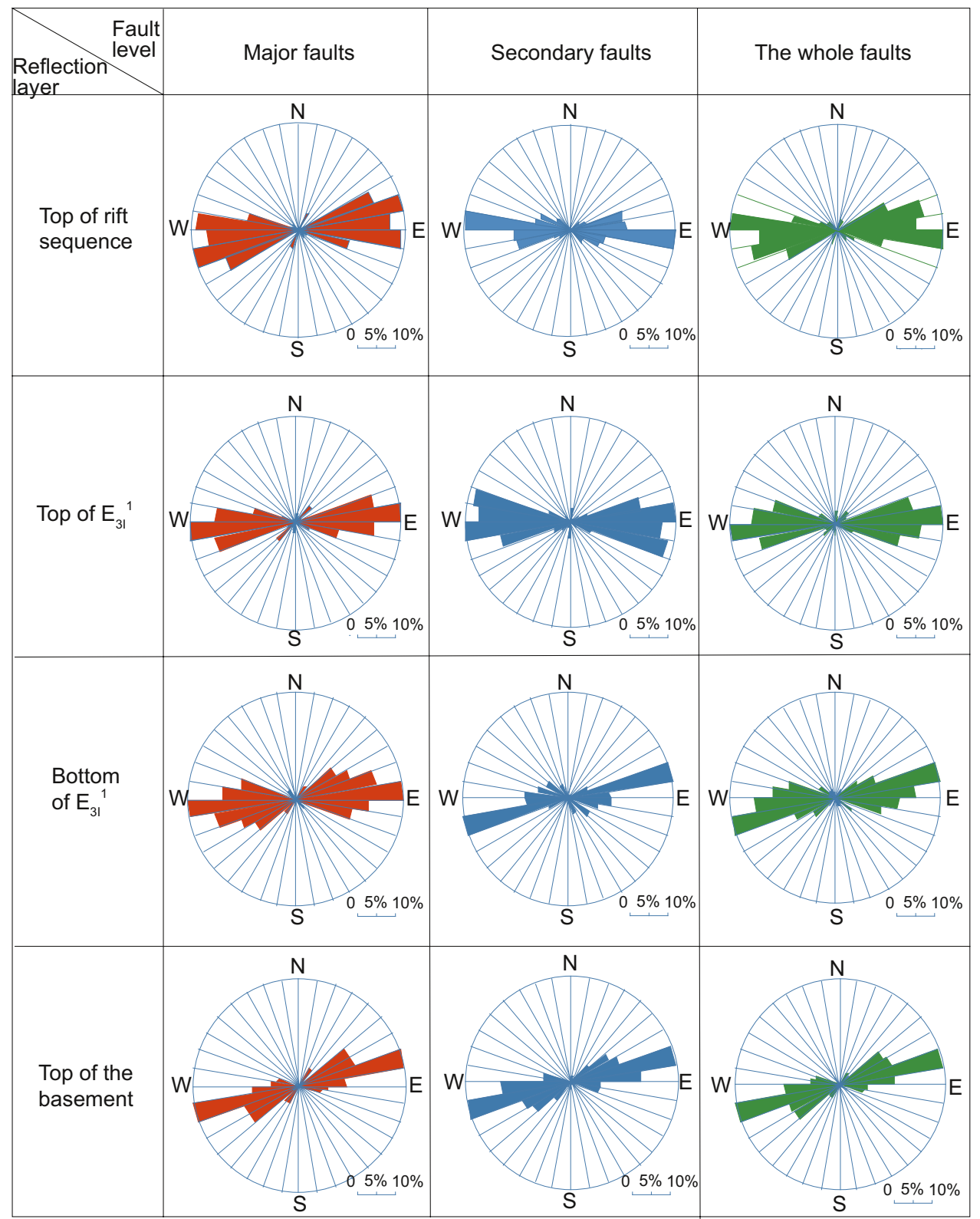

Fig. 4 Rose diagram of fault strike in different reflection layers in the Weixinan Sag

\section{Experimental model}

The sandbox model was used in the experiment, and the simulation area was a rectangular region (Fig. 3(a)), which covered most of the Weixinan Sag. The simulation target was the structural deformation of $\mathrm{E}_{31}{ }^{1}$, which is the main reservoir in the Weixinan Sag. Based on the results of the conceptual sandbox modeling study, an experimental model of oblique extension with multiple pre-existing weaknesses was designed and the structural characteristics of the Weixinan Sag were successfully reproduced. The experimental model was based on the conceptual modeling of one-side extension. The driving-heads stretched the inhomogeneous elastic rubber basement to cause extension deformation with pre-existing fabrics set on the basement. The design is stated as follows (Fig. 5).
1) The model basement and pre-existing fabrics: The model basement was a combination of elastic rubber sheet and canvas (to simulate non-deformed uplift area in the north), which were connected together. The geometry of the canvas border was determined by the simplified plane geometry of Fault No.1. A block of polystyrene plastic with a dip angle of $60^{\circ}$ on one side was attached to the canvas to simulate the pre-existing No.1 fault. Another block of polystyrene plastic was put on the rubber sheet in the location of the Weixinan Low Uplift at the hanging wall of Fault No.3 to simulate the pre-existing fault and the relatively rigid characteristics of the Weixinan Low Uplift. A small block of polystyrene was also put at the footwall of Fault Hai-1 to simulate the pre-existing fault of Hai-1 (Fig. 5(b)). A weak rubber belt was set along Fault No.2 to simulate the pre-existing fault. The specific locations of all pre-existing faults were determined according 


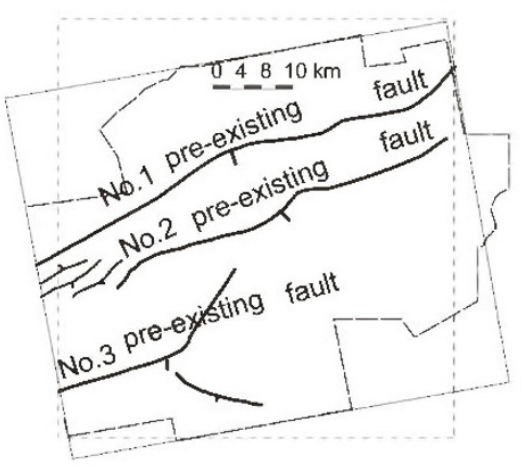

(a)

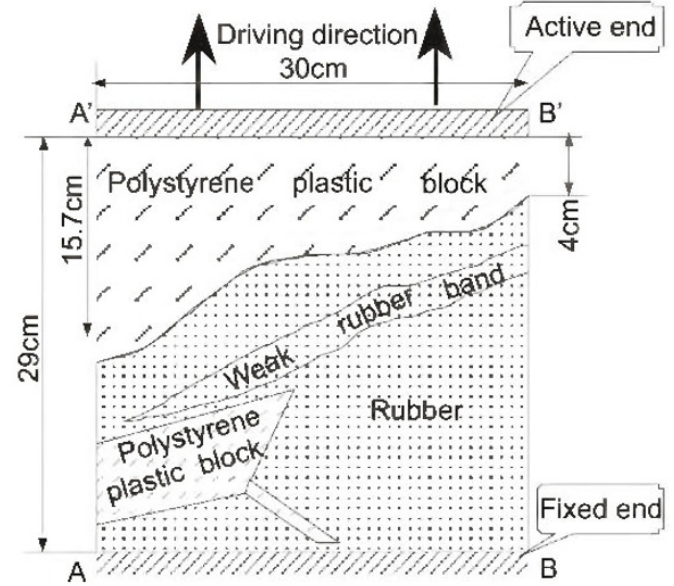

(b)

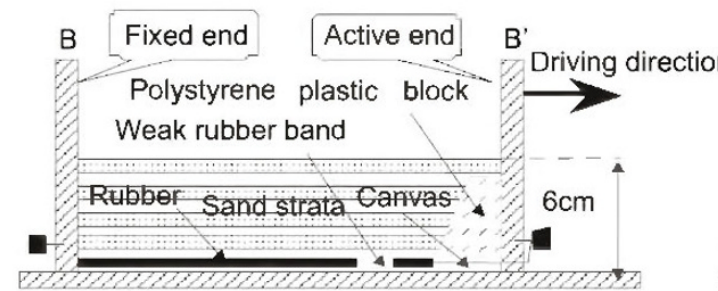

(c)

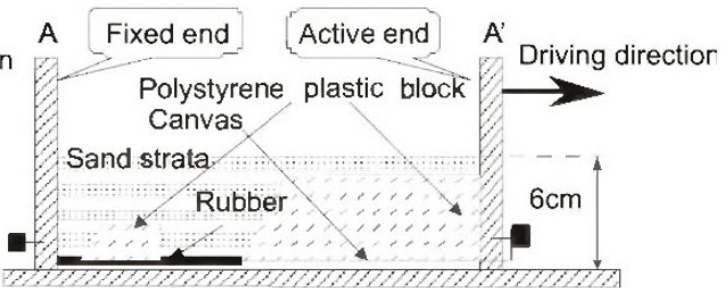

(d)

Fig. 5 Experimental model of the Weixinan sandbox modeling. (a) Location of pre-cxisting faults after balanced restoration; (b) Plan view; (c) A-A section view; (d) B-B section view, section location seen in (b)

to the locations after balanced restoration. The average strike of pre-existing fault No.1, No.2, No.3 and Hai-1 is $70^{\circ}, 67^{\circ}$, $74^{\circ}$ and $124^{\circ}$ respectively, and they are all oblique to the N-S direction of extension $\left(359^{\circ}\right)$ at an angle of $71^{\circ}, 68^{\circ}, 75^{\circ}$ and $125^{\circ}$ respectively.

2) The amount and direction of extension: The driving heads were located on the north end and the total displacement was $6.9 \mathrm{~cm}$. Because of the irregular border, the original lengths of the deformed area were not constant at different locations, with an average extension of about $35 \%$. The model extension amount is determined from actual data and a series of tests. The direction of model extension was nearly north-south $\left(359^{\circ}\right)$. It is based on the average direction of secondary faults in the reflection layer at the top of the rifting sequence.

3) The driving direction and rate $(0.04 \mathrm{~mm} / \mathrm{s})$ were kept constant to simulate the state that the direction of regional extension was unchanged during the deposition of the Liushagang and Weizhou formations - the main stage of fault system development in the sag.

The experimental results have successfully reproduced the main features of the fault system in the Weixinan Sag (comparison between Fig. 3(a) and Fig. 3(b)), including (1) the distribution and assemblage characteristics of sagcontrolled Fault No.1, No.2 and No.3, particularly the special assemblage and evolution of Fault No.2 and No.3, (2) different characteristics of the fault system distribution on both sides of No.0 transfer fault zone, (3) four directions of fault trending and the changes of fault direction at different deformation stages, (4) a systematic difference in dip direction between faults in the area to the east of Fault No.3, and (5) the uplift and depression distribution.

In order to confirm the results, experiments were repeated and almost identical results were obtained.

\section{Description of experimental process and results}

Stage 1 (extension amount $0-5 \%$ ): Soon after extension started, the entire Fault No.3 (marked as "1" in Fig. 6(b)-1, the number indicating the order of fault formation) formed simultaneously. Then Fault No.1 (marked as "2" in Fig. 6(b)1) was formed gradually from west to east. A fault (marked as "3" in Fig. 6(b)-1) on the northeast-trending line of Fault No.3 and dipping oppositely, followed.

Stage 2 (extension amount 5\%-12\%): With the continuation of extension, Fault No.2 (marked as " 4 " and " 5 " in Fig. 6(b)-2) began to form. Fault No.2 was divided into two segments, the south-dipping east segment and north-dipping west segment, and they were formed almost simultaneously. At the same time, echelon fault zones began to form in the area between Fault No.2 and Fault No.3. Fault No.3 and No.1 were growing, but the activity of Fault No.3 was much stronger.

Stage 3 (extension amount 12\%-22\%): In the mid-late stage of extension, the throw of Fault No.3 continued to 
increase and the controlling sag became deeper. Fault No.2 changed gradually from one continuous ENE-trending fault to a number of nearly EW-trending en echelon array faults, and the fault marked as "7" (Fig. 6(b)-3) began to form. With further increase of extension, numerous nearly EW-trending faults formed. At stage 3, the framework of the fault system had formed (comparing Fig. 6(b)-3 with Fig. 6(b)-4).
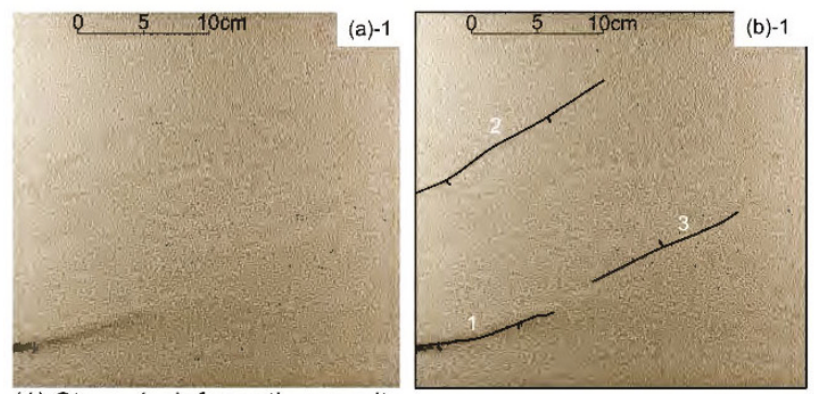

(1) Stage 1: deformation result

The extension displacement $d=0.90 \mathrm{~cm}$, extension amount $=4.63 \%$
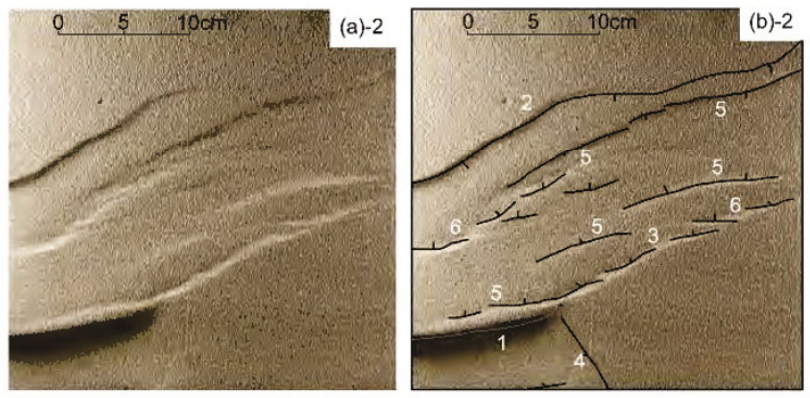

(2) Stage 2: deformation result

The extension displacement $d=2.08 \mathrm{~cm}$, extension amount $=10.7 \%$


(3) Stage 3: deformation result

The extension displacement $d=4.10 \mathrm{~cm}$, extension amount $=21.09 \%$
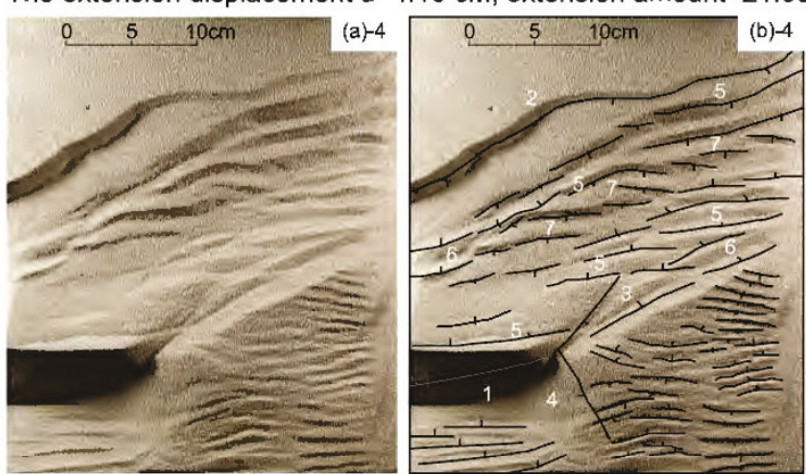

(4) Final stage: deformation result

The extension displacement $d=6.93 \mathrm{~cm}$, extension amount $=35.65 \%$

Fig. 6 Results of different deformation stages of sandbox modeling and interpretation (the number is fault formation order). (a): sandbox modeling results; (b): interpretation of sandbox modeling results
Stage 4 (extension amount 22\%-35.6\%): In the late stage of extension, the throw of all faults increased, while the length and number of faults were nearly unchanged with continuous increase of extension. The major faults became more significant, but the structural frame was unchanged (Fig. 6(b)-4).

\section{Analysis of sandbox modeling results}

The results of actual sandbox modeling of the Weixinan Sag show that the fault formation and evolution with multiple pre-existing weaknesses are quite different from those of a simple extension model. The pre-existing fabrics play a fundamental role in fault formation and evolution in rift basins. The following is the basic knowledge of fault formation and evolution insight from the actual sandbox modeling of the Weixinan Sag.

\subsection{The size and formation order of faults}

Weakness reactivation fault (i.e. weakness controlling fault, such as Fault No.1, No.2 and No.3 in the Weixinan Sag) and weakness related fault (i.e. synthetic and/or antithetic fault of weakness reactivation fault, such as the faults marked as " 3 " and " 5 " in Fig. 6(b)-2) formed much earlier than the distant-weakness faults (faults far away from and with little or no relationship to the weakness), and weakness reactivation faults usually constitute major faults. When weakness reactivation fault terminates suddenly (i.e. Fault No.3), a transfer fault zone (No.0 transfer fault zone) will occur, and the fault characteristics will change greatly (Fault No. 3 changes into numerous, small scale, EW-trending faults in the east). The common order of fault formation is that the weakness reactivation fault is created first, then the weakness related fault follows, and the distant-weakness fault is formed at last. The distant-weakness faults are usually small faults.

\subsection{Fault length and number of faults}

The results of sandbox modeling showed that the fault number versus fault length (Fig. 7) might not have a negative power distribution mode $\left(N_{\mathrm{F}}=k L^{-d}, N_{\mathrm{F}}\right.$ : fault number with a given length, $L$ : the length of single fault, $k$ and $d$ : coefficients related to deformation). Although the final experimental results of the Weixinan Sag (dark green column in Fig. 7) showed this general trend, the results of other deformation stages (stage 1, 2, 3 in Fig. 7) in the experiment did not follow this law, particularly in stage 1 , where only longer faults existed (fault length $>100 \mathrm{~mm}$ ).

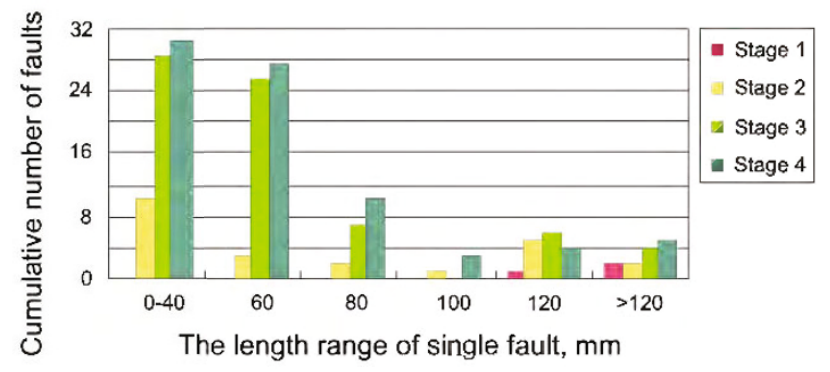

Fig. 7 The histogram of cumulative number of faults versus length of single fault at different extension stages in the sandbox modeling (the corresponding deformation stage is seen in Fig. 6) 
Experimental results showed that, with an increase of extension, the cumulative length of faults increases (Fig. $8(\mathrm{a})$ ), whereas the average fault length showed non-linear changes (Fig. 8(b)). The increasing cumulative length of faults was mainly contributed by the formation of new faults instead of fault propagation. The average fault length showed a decreasing trend with an increase of extension in the Weixinan Sag (Fig. 8).
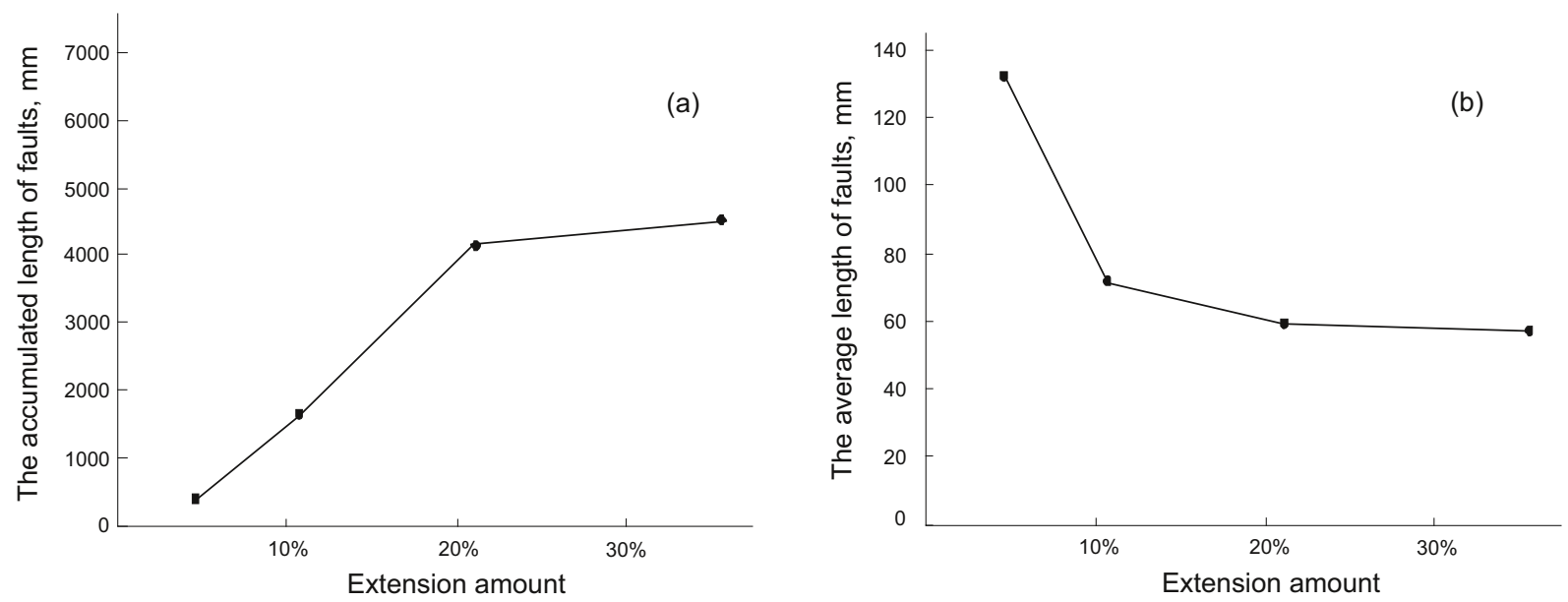

Fig. 8 The relationship between accumulated fault length (a), average fault length (b) and extension amount in sandbox modeling

\subsection{Fault strike, groups and the origin of complicated fault system}

Experiment results showed that weakness reactivation fault developed mainly along pre-existing weakness and weakness-related faults developed parallel (or sub-parallel) to pre-existing weakness, while distant-weakness faults developed nearly perpendicular to the extension direction. As a result, fault strike, groups and assemblage were closely related to the property and distribution of pre-existing weakness.

At the early deformation stage, the fault strike was mainly controlled by the pre-existing weaknesses (Fig. 9(a)). From the middle to late deformation stage, the fault strike is controlled by pre-existing weaknesses and extension direction together, and the effect of extension direction became more important (Figs. 9(b), 9(c) and 9(d)). As the average strike of the pre-existing weaknesses in the Weixinan Sag is not perpendicular to the extension, the average fault strike is characterized by a clockwise rotation (Figs. 9(a), 9(b), 9(c) and 9(d)). The distribution of fault strikes is a combined response of three mutually independent factors, i.e., the distribution of pre-existing faults, regional extension direction, and the progressive extension process (extension amount). Systematic change (difference decreasing from bottom to top) of the difference between the strikes of major fault and secondary fault in the Weixinan Sag may be related to progressive sediment filling, which may weaken the role of pre-existing weaknesses.

Each weakness, which can be reactivated during extension, will form at least one group of faults (weakness activation faults and weakness-related faults) in progressive extension. So, if the extension is large enough, and the preexisting weaknesses are not perpendicular to the extension direction and not parallel to each other, the number of fault groups $\left(n_{\mathrm{GF}}\right)$ is equal to or greater than the number of preexisting weakness groups $\left(n_{\mathrm{GW}}\right)$ plus $1\left(n_{\mathrm{GF}} \geq n_{\mathrm{GW}}+1\right)$, a complicated fault system can, therefore, be formed with the existence of multiple pre-existing weaknesses under a fixed extension direction.

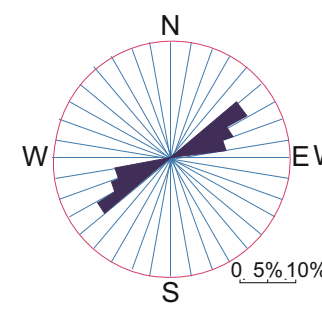

(a)

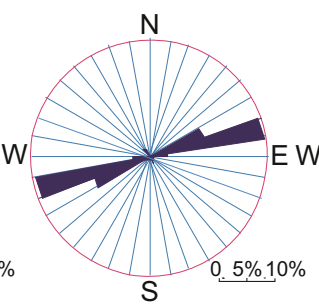

(b)

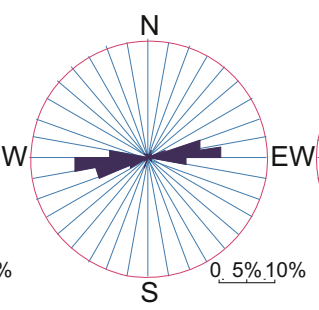

(c)



(d)

Fig. 9 Rose diagram of fault strike at different deformation stages (corresponding the fault system in different deformation stages seen in Fig. 6) in the Weixinan sandbox modeling 


\section{Conclusions}

The complicated fault systems of an actual rift basin area can be successfully reproduced by sandbox modeling with multiple pre-existing weaknesses. The complicated fault system in the Weixinan Sag formed gradually in the nearly N-S extension direction with multiple pre-existing weaknesses.

In rift basin, weakness reactivation faults and weakness related faults formed much earlier than the distant-weakness faults. The common order of fault formation is as follows: the weakness reactivation faults first, followed by the weakness related faults, and then the distant-weakness faults.

Weakness reactivation faults and weakness related faults develop mainly along or parallel to pre-existing weakness, while distant-weakness faults develop nearly perpendicular to the extension direction. At the early deformation stage, the fault strike is mainly controlled by the pre-existing weaknesses. From the middle to late deformation stage, the fault strike is controlled by pre-existing weaknesses and extension direction together, and the effect of extension direction becomes more important. The average strike of faults will change in progressive extension. A complicated fault system can be formed in a fixed extension direction with the existence of multiple pre-existing weaknesses.

The relationships of fault length versus displacement, and the fault number and length variation are closely related to the property and distribution of pre-existing weaknesses, but there is not a unique law.

\section{Acknowledgements}

We would like to thank Prof. Scott Huang of University of Alaska Fairbanks, the U.S.A. for improving the English manuscript. This study was supported by China National Major Project of Oil and Gas (2011ZX05023-004-012, 2011ZX05006-006-02-01) and China Natural Science Foundation (Grant No. 40772086).

\section{References}

Acocella V, Gudmundsson A and Funiciello R. Interaction and linkage of extension fractures and normal faults: examples from the rift zone of Iceland. Journal of Structural Geology. 2000. 22: 1233-1246

Aragón-Arreola M, Morandi M, Martín-Barajas A, et al. Structure of the rift basins in the central Gulf of California: Kinematic implications for oblique rifting. Tectonophysics. 2005. 409(1-4): 19-38

Barnett J A M, Mortimer J, Rippon J H, et al. Displacement geometry in the volume containing a single normal fault. AAPG Bulletin. 1987. 71: 925-937

Boccaletti M, Bonini M, Mazzuoli R, et al. Quaternary oblique extensional tectonics in the Ethiopian Rift (Horn of Africa). Tectonophysics. 1998. 287(1-4): 97-116

Cartwright J A, Trudgill B D and Mansfield C S. Fault growth by segment linkage: An explanation for scatter in maximum displacement and trace length data from the Canyonlands Grabens of SE Utah. Journal of Structural Geology. 1995. 17: 1319-1326

Crider J G. Oblique slip and the geometry of normal-fault linkage: Mechanics and a case study from the basin and range in Oregon. Journal of Structural Geology. 2001. 23: 1997-2009

Dooley T, McClay K R and Pascoe R. 3D analogue models of variable displacement extensional faults: applications to the Revfallet fault system, offshore mid-Norway. Geological Society Special Publications. 2003. 212: 151-167

Eisenstadt G and Sims D. Evaluating sand and clay models: do rheological differences matter? Journal of Structural Geology. 2005. 27(8): 1399-1412

Huggins P, Watterson J, Walsh J J, et al. Relay zone geometry and displacement transfer between normal faults recorded in coal-mine planes. Journal of Structural Geology. 1995. 17(12): 1741-1755

Karlstrom L and Manga M. Origins and implications of zigzag rift patterns on lava lakes. Journal of Volcanology and Geothermal Research. 2006. 154(3-4): 317-324

Lu K Z, Qi J F, Dai J S, et al. A Cenozoic Tectonic Model in Bohai Bay Petroliferous Basins. Beijing: Geological Press. 1997. 72-86 (in Chinese)

Ma J. Tectophysics Introduction. Beijing: Seismological Press. 1987. 1-14 (in Chinese)

McClay K R. Extensional fault systems in sedimentary basins: A review of analogue model studies. Marine and Petroleum Geology. 1990. 7(1): 206-233

McClay K R and Ellis P G. Geometries of extensional fault systems developed in model experiments. Geology. 1987. 15(4): 341-344

McClay K R and White M J. Analogue modeling of orthogonal and oblique rifting. Marine and Petroleum Geology. 1995. 12(1): 137151

Morley C K, Haranya C, Phoosongsee W, et al. Activation of rift oblique and rift parallel pre-existing fabrics during extension and their effect on deformation style: examples from the rifts of Thailand. Journal of Structural Geology. 2004. 26(10): 1803-1829

Morley C K. Variations in late Cenozoic-recent strike-slip and obliqueextensional geometries, within Indochina: The influence of preexisting fabrics. Journal of Structural Geology. 2007. 29(1): 36-58

Patton T L. Sandbox models of downward-steepening normal faults. AAPG Bulletin. 2005. 89(6): 781-797

Peacock D C P and Sanderson D J. Displacements, segment linkage and relay ramps in normal fault zones. Journal of Structural Geology. 1991. 13(6): 721-733

Tian Z Y and Zhang Q C. Discussion of China's Petroliferous Sedimentary Basins. Beijing: Petroleum Industry Press. 1996. 36-48 (in Chinese)

Tong H M. Plane sandbox modeling of the complicated Zhangjuhe faulted block and its implication, the Bohai Bay Basin. Geological Review. 2003. 49(3): 305-310 (in Chinese)

Tong H M and Yin A. Reactivation tendency analysis: A theory for predicting the temporal evolution of pre-existing weakness under uniform stress state. Tectonophysics. 2011. 503(3-4): 195-200

Tong H M, Cai D S, Wu Y P, et al. Activity criterion of pre-existing fabrics in non-homogeneous deformation domain. Science in China (Earth Sciences). 2010. 53(8): 1-11

Walsh J J and Watterson J. Analysis of the relationship between displacements and dimensions of faults. Journal of Structural Geology. 1988. 10: 239-247

Withjack M O and Jamison W R. Deformation produced by oblique rifting. Tectonophysics. 1986. 126(2-4): 99-124

Yan Y, Xia B, Lin G, et al. The sedimentary and tectonic evolution of the basins in the north margin of the South China Sea and geodynamic setting. Marine Geology \& Quaternary Geology. 2005. 25(2): 56-64 (in Chinese)

Zhou J X, Xu F Y, Wei C G, et al. Shortening of analogue models with contractive substrata: Insights into the origin of purely landwardvergent thrusting wedge along the Cascadia subduction zone and the deformation evolution of Himalayan-Tibetan orogen. Earth and Planetary Science Letters. 2007. 260(1-2): 313-327

(Edited by Hao Jie) 